SHRM Survey Findings

\title{
Health Care Reform-2017 Update
}




\section{Table of Contents}

\section{About SHRM}

The Society for Human Resource Management (SHRM) is the world's largest HR professional society, representing 285,000 members in more than 165 countries. For nearly seven decades, the Society has been the leading provider of resources serving the needs of $\mathrm{HR}$ professionals and advancing the practice of human resource management. SHRM has more than 575 affiliated chapters within the United States and subsidiary offices in China, India and United Arab Emirates.

\section{Introduction}

4 Key Findings

5 Future of the ACA

9 ACA Compliance

15 Health Care Costs

20 ACA Impact on Health Care Benefits

26 Demographics

30 Methodology 


\section{Introduction}

...employersponsored plans are the bedrock of the U.S. health care system.
An affordable, innovative and efficient health care system is essential to ensuring a productive and competitive U.S. workforce, as well as a better quality of life for all Americans. As the providers of health care coverage to more than 177 million Americans and their families, employer-sponsored plans are the bedrock of the U.S. health care system. The Affordable Care Act (ACA), enacted in 2010, brought about major reforms in health care coverage in the United States, affecting both insured and self-insured employer-sponsored health care plans. The purpose of this research is to examine how organizations are implementing the ACA and what impact it has had on employersponsored health benefits.

In February 2017, the Society for Human Resource Management (SHRM) surveyed U.S. employers to learn about their opinions, actions and challenges related to the ACA. SHRM has conducted research on health care reform since 2013, and data are compared with previous years where possible.

The results of this research will help inform HR professionals, executives and public policy makers on the state of employment-based health care benefits in U.S. organizations. Specifically, these findings serve as an indicator of health benefits offerings and demonstrate trends in employer-sponsored health benefits offerings. 


\section{Key Findings}

Employer-sponsored health care plan costs continue to increase year over year for the majority of organizations.

Similar to previous years, health care coverage costs increased for nearly eight out of 10 organizations (79\%) in 2017 . On average, these organizations reported an $11 \%$ increase in costs. One-quarter (25\%) saw an increase of $5 \%$ or less, $41 \%$ reported an increase of $6 \%$ to $10 \%$, and $34 \%$ had an increase of more than $10 \%$.

Organizations are waiting to assess the impact of the excise tax. Fourteen percent of organizations have already taken action to avoid paying the excise tax. Some (44\%) are waiting for final guidance before taking any action or plan to do an analysis to avoid paying the tax. Just $1 \%$ have opted to pay the tax, and $15 \%$ have not yet considered the impact of the tax.
Taxing insurance contributions could result in higher health care costs for employees. If insurance contributions lose tax-exempt status, two-thirds of organizations $(67 \%)$ anticipate that employee health insurance premiums would increase, and $60 \%$ expect increased out-of-pocket health care costs.

\section{Prohibiting preexisting condition} exclusions is the most important element of the ACA, according to HR professionals. Eighty-three percent of $\mathrm{HR}$ professionals agreed that not allowing preexisting condition exclusions was one of the most important aspects of the ACA, followed by preventative care coverage with no cost-sharing (52\%). 


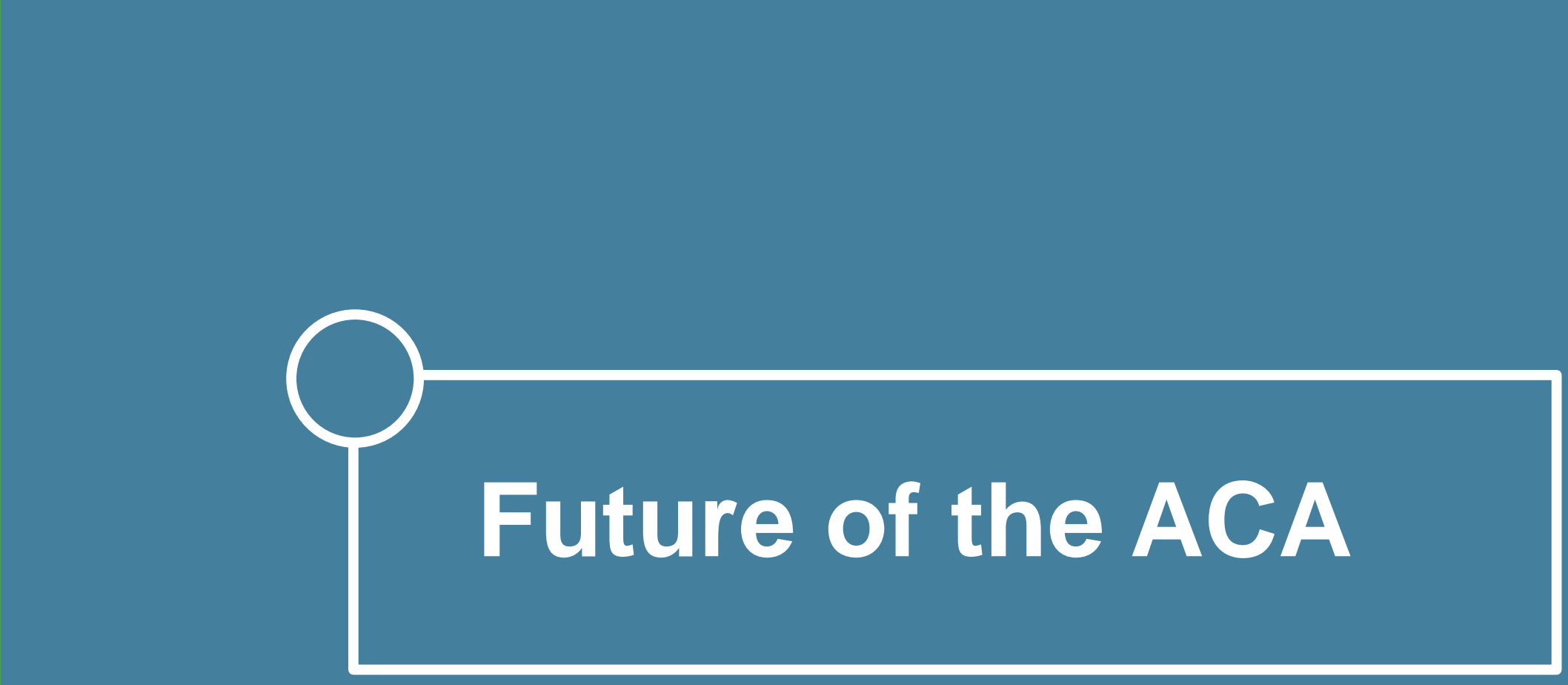




\section{Future of}

\section{the ACA}

- Stay up to date about proposed legislative changes to the ACA that will affect the HR profession and the workplace.

- Take action! Advocate on behalf of $\mathrm{HR}$ at advocacy.shrm.org

\section{Keep coverage for those with preexisting conditions}

When asked about the three most important elements of the ACA, HR professionals overwhelmingly agreed that coverage with no preexisting condition exclusions tops the list.

No preexisting condition exclusions $83 \%$

Preventative care coverage with no

cost-sharing
No lifetime limits on the value of
benefits

cost-sharing
No lifetime limits on the value of
benefits

cost-sharing
No lifetime limits on the value of
benefits

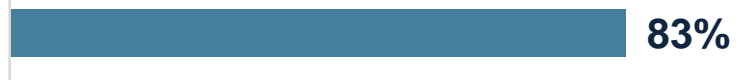

Dependent children coverage up to

Insurance market reform that

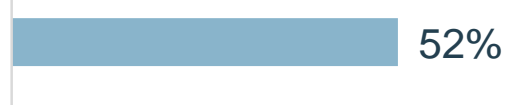

$52 \%$

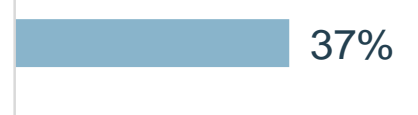
promotes competition and choice

Health care coverage availability for most Americans

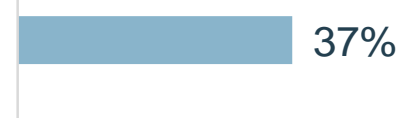

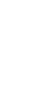

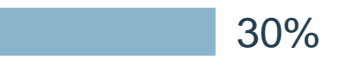

An employer-based health care coverage system

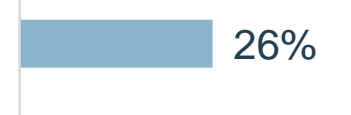

Other

$3 \%$

Note: $n=893$. Percentages do not total $100 \%$ due to multiple response options. Respondents were allowed to select up to three options. Respondents who answered "don't know" were excluded from this analysis. 


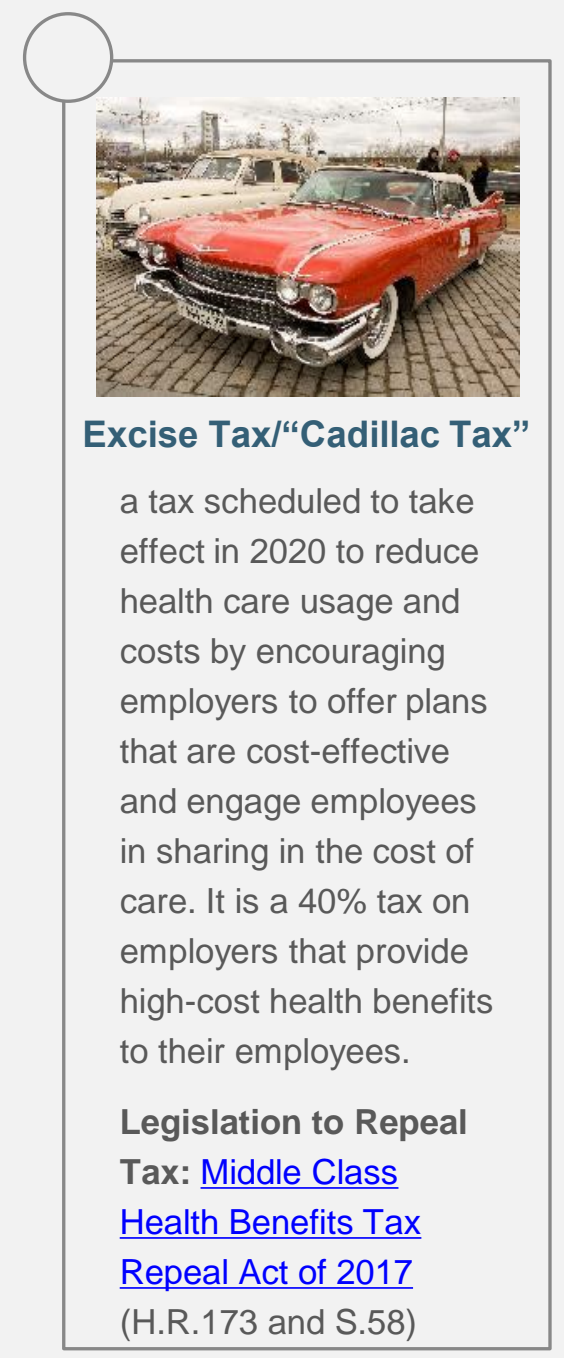

\section{Organizations are waiting to assess the impact of excise tax}

Three out of five organizations (60\%) have not yet taken action to evaluate the impact of the excise tax. Of these organizations, $91 \%$ said the delay of the tax until 2020 has been helpful.

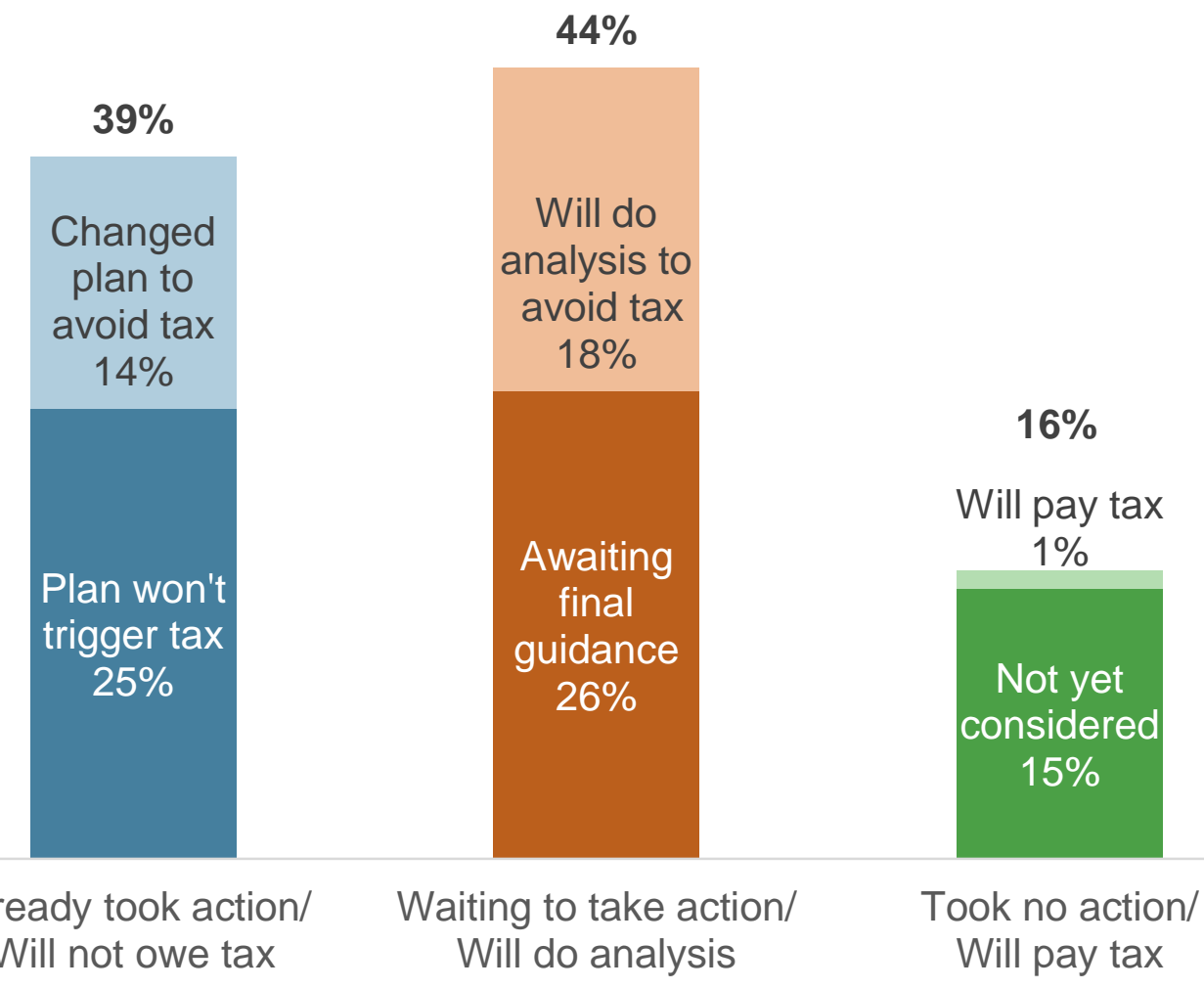

Note: $n=673$. Percentages do not total $100 \%$ due to rounding. 


\section{Taxing insurance contributions could result in higher employee health care costs}

If Congress decides to tax employer and employee insurance contributions, costs for employees are expected to increase in terms of health care premiums and out-of-pocket heath care expenditures.

Health insurance premium costs for employees
$5 \%$ $28 \%$
$67 \%$

Out-of-pocket health care costs for employees

$\begin{array}{lll}5 \% & 35 \% & 60 \%\end{array}$

Coverage for brand-name prescription drugs $26 \%$ $47 \%$

$27 \%$

Coverage for specific types of medical procedures/conditions

Number of health care plan options

$22 \%$ $65 \%$

$14 \%$

- Decrease $\quad$ Stay the same $\quad$ Increase

Note: $n=815-820$. Percentages may not total $100 \%$ due to rounding. 


\section{$66 \%$}

\section{of organizations} outsourced at least some of the ACA information reporting requirements.

2017 ACA Deadlines (2016 tax year)

1. Feb. 28, 2017: 1094-B/C and 1095- $C$ due to the IRS if filing on paper.

2. March 2, 2017: $1095-B / C$ due to employees.

3. March 31, 2017: 1094-B/C and 1095-C due to the IRS if filing electronically.

\section{Reporting requirements are HR's biggest ACA challenge}

When asked about the three main challenges in complying with the ACA, organizations cited reporting requirements, followed closely by complexity of the law and the time investment.

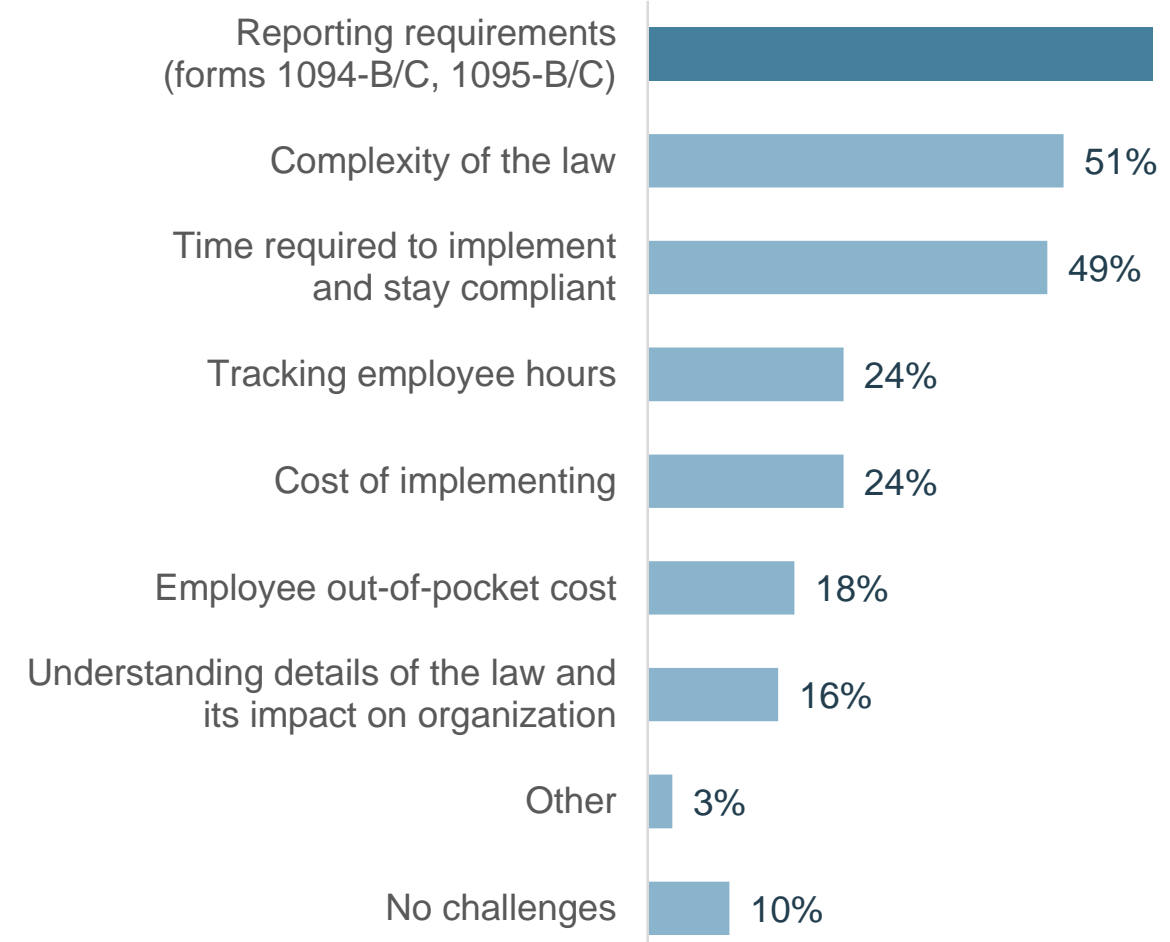

Understanding details of the law and its impact on organization

Note: $n=856$. Percentages do not total $100 \%$ due to multiple response options. Respondents were allowed to select up to three options. Respondents who answered "don't know" or "N/A, my organization is not implementing provisions of the ACA" were excluded from this analysis. 

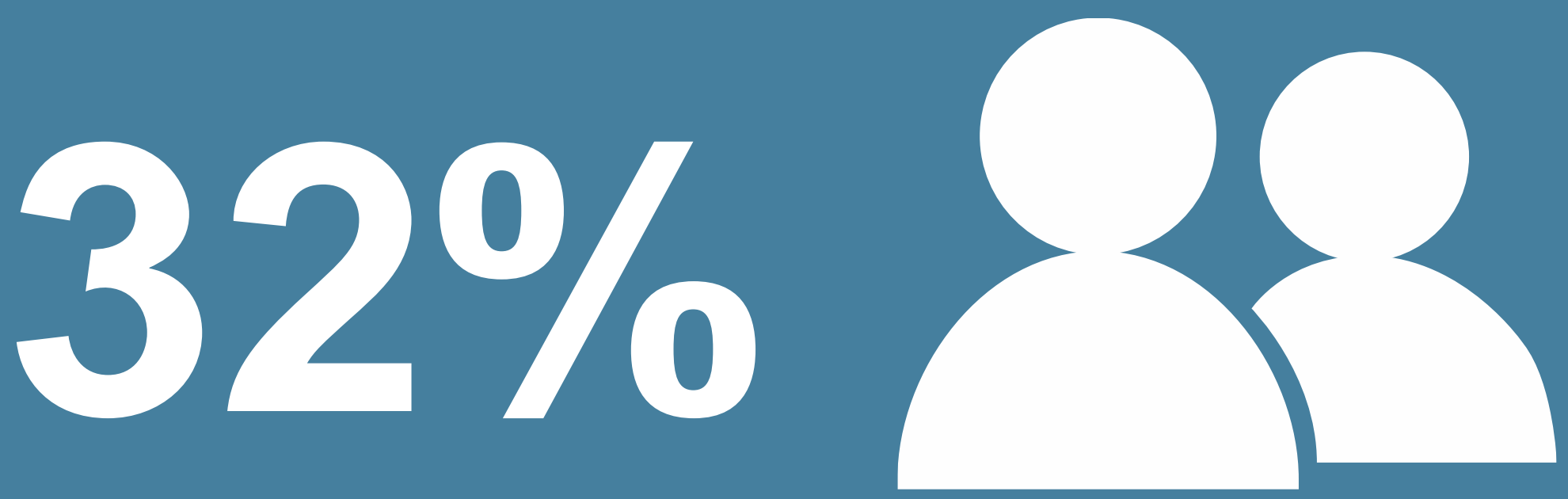

of organizations hire

a seasonal workforce

Note: $n=841$. Respondents who answered "don't know" were excluded from this analysis. 
The ACA has two different definitions of seasonal workers and uses different lengths of service for determining:

1. If an organization is a small or large employer.

2. Which employees must be offered health insurance.

SHRM advocates in support of legislation that would provide one clear definition of seasonal employment and simplify the determination of applicable large employer size.

\section{Seasonal workforce causes additional ACA challenges}

More than two-thirds of organizations with a seasonal workforce (69\%) report additional challenges in complying with the ACA. Tracking employee hours was the most common difficulty.

\section{Tracking or monitoring employee} hours and status

Understanding how the ACA applies to seasonal employees
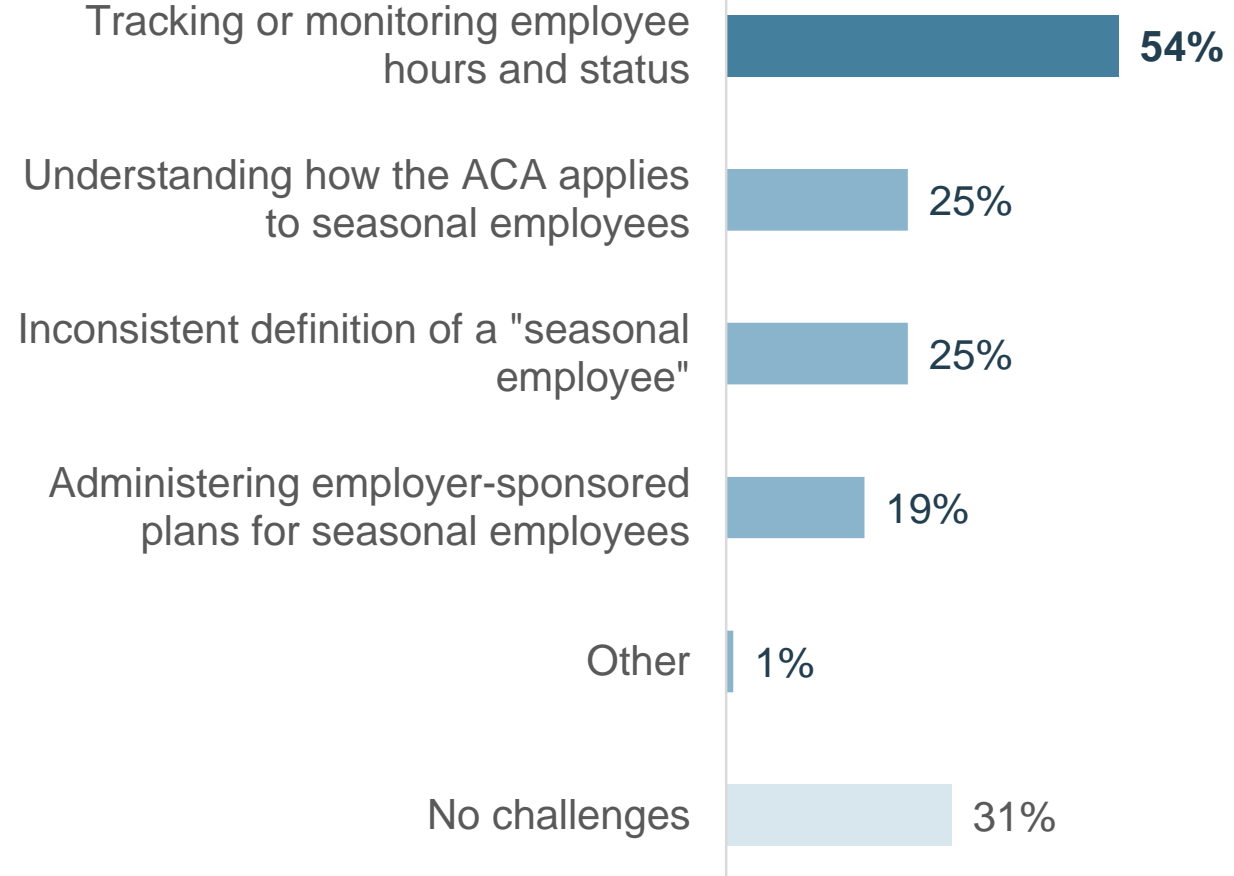

Note: $n=259$. Percentages do not total $100 \%$ due to multiple response options. Only organizations with a seasonal workforce were asked this question. Respondents who answered "not sure" were excluded from this analysis. 


\section{ACA compliance requires ongoing education for HR}

The two biggest effects of the ACA on HR are keeping employees informed and training HR on ACA compliance.

- Latest Updates on the $\underline{A C A}$

Members Only

- Complying with and leveraging the ACA

- Communicating with employees about health care benefits under the ACA

Member Pricing

SHRM eLearning: Benefits Training

- Health Care Cost and Quality

- Health Care Delivery Models

- HAS and HRA Basics

- Overview of the ACA

Communicate impact to employees

Train HR on the ACA and its impact

Analyze short-term financial impact

Hire/work with external legal/benefits counsel

Analyze long-term financial impact

Partner with health provider to design plan

Develop new health care strategy

Communicate impact to retirees

Hire consultants for staffing strategy

Plan for automatic enrollment in health care
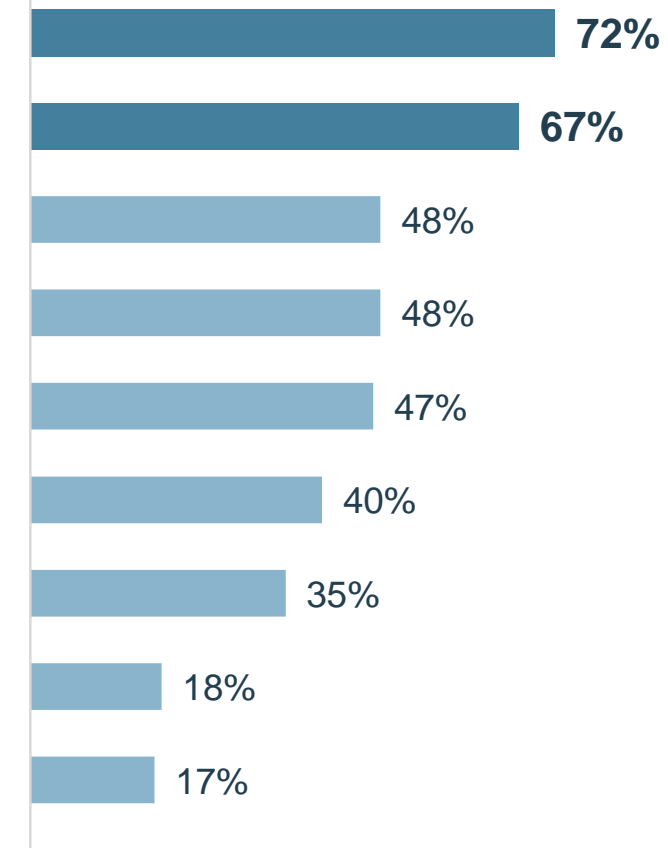

$35 \%$

Note: $n=813$. Percentages do not total $100 \%$ due to multiple response options. 


SHRM Resources
$\underline{\text { SHRM HR Vendor }}$
Directory
- More than 280 companies
providing health and
welfare benefits
SHRM HR Help
- Express requests
- Tools and samples
- Member forums
- Ask an advisor
Latest Updates on the
$\underline{\text { ACA }}$

\section{Many organizations rely on external resources for the ACA}

Most organizations (72\%) use an insurance broker as a resource for the ACA, although this percentage is slightly lower than in 2015 and 2013. Compared with 2015 , more organizations are using consultants, up to $38 \%$ from $31 \%$.
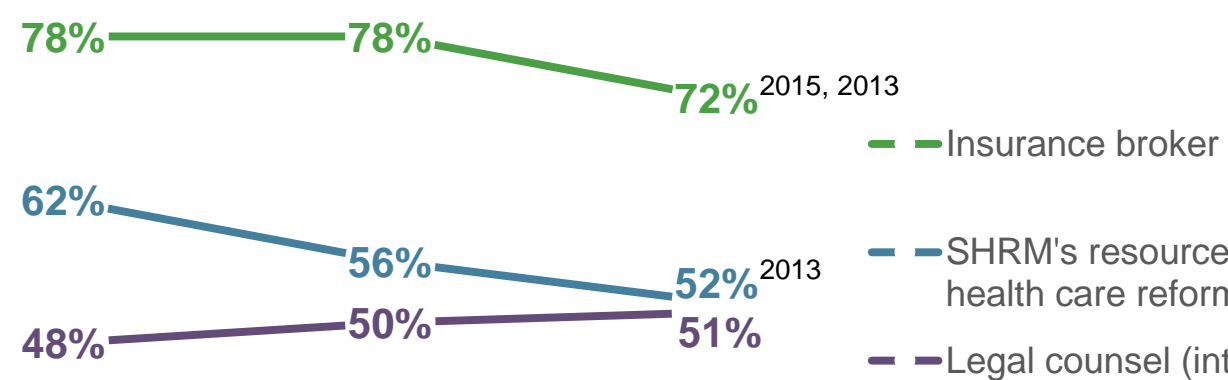

- -SHRM's resources on the health care reform law

- - Legal counsel (internal or
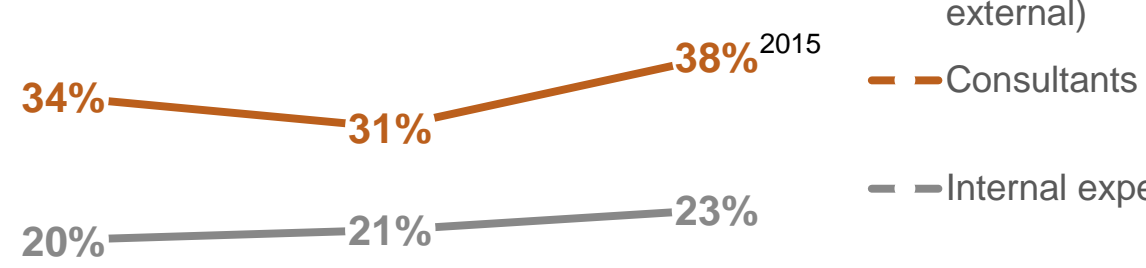

- - Internal experts

- - Other

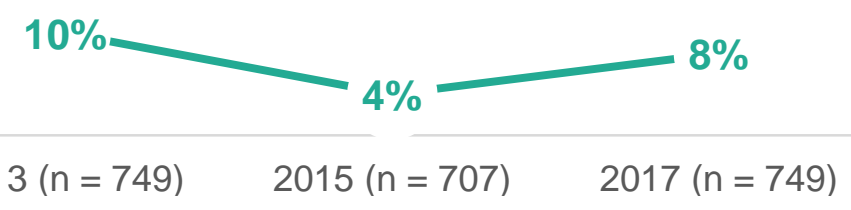

Note: Percentages do not equal $100 \%$ due to multiple response options.

2015 Statistically significant difference from 2015.

2013 Statistically significant difference from 2013. 


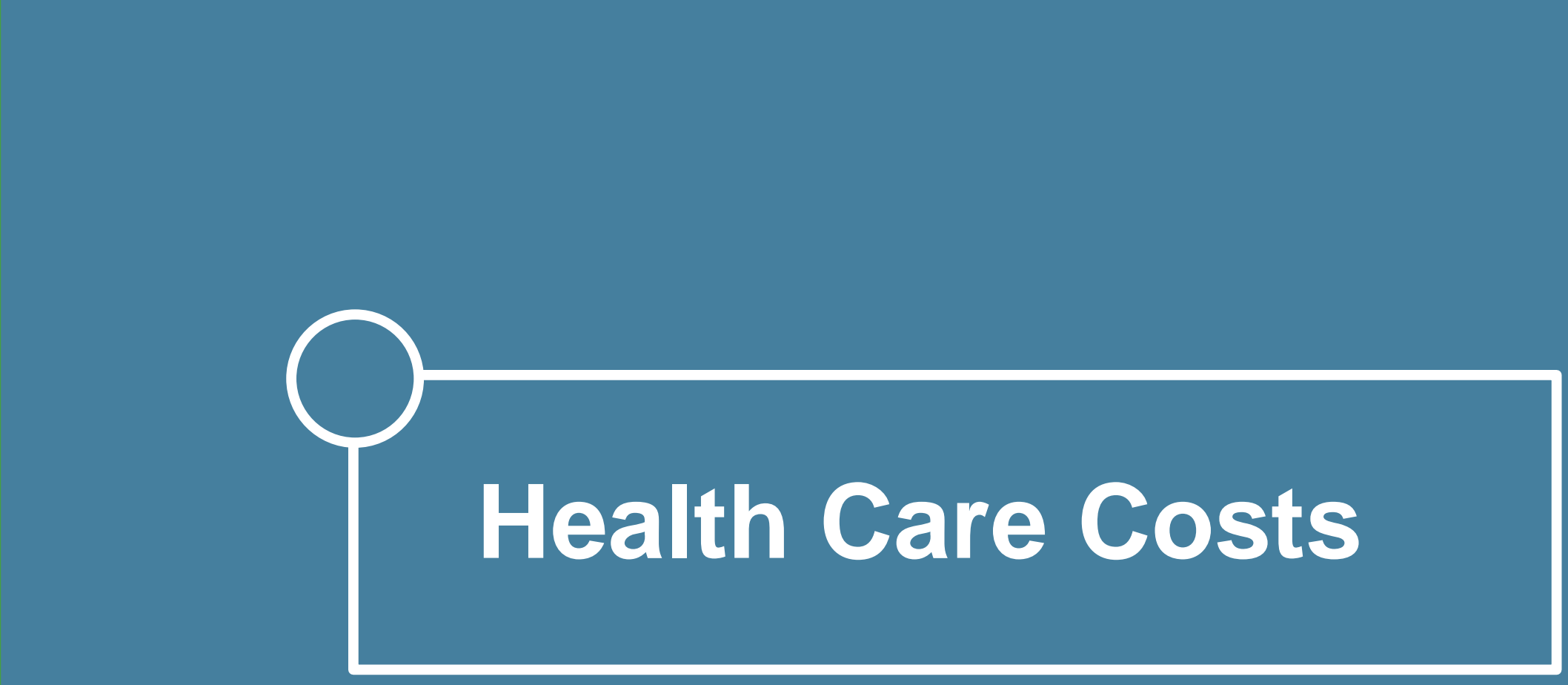




\section{Most organizations' health care costs increased again in 2017}

From 2016 to 2017, health care costs increased 11\% on average.

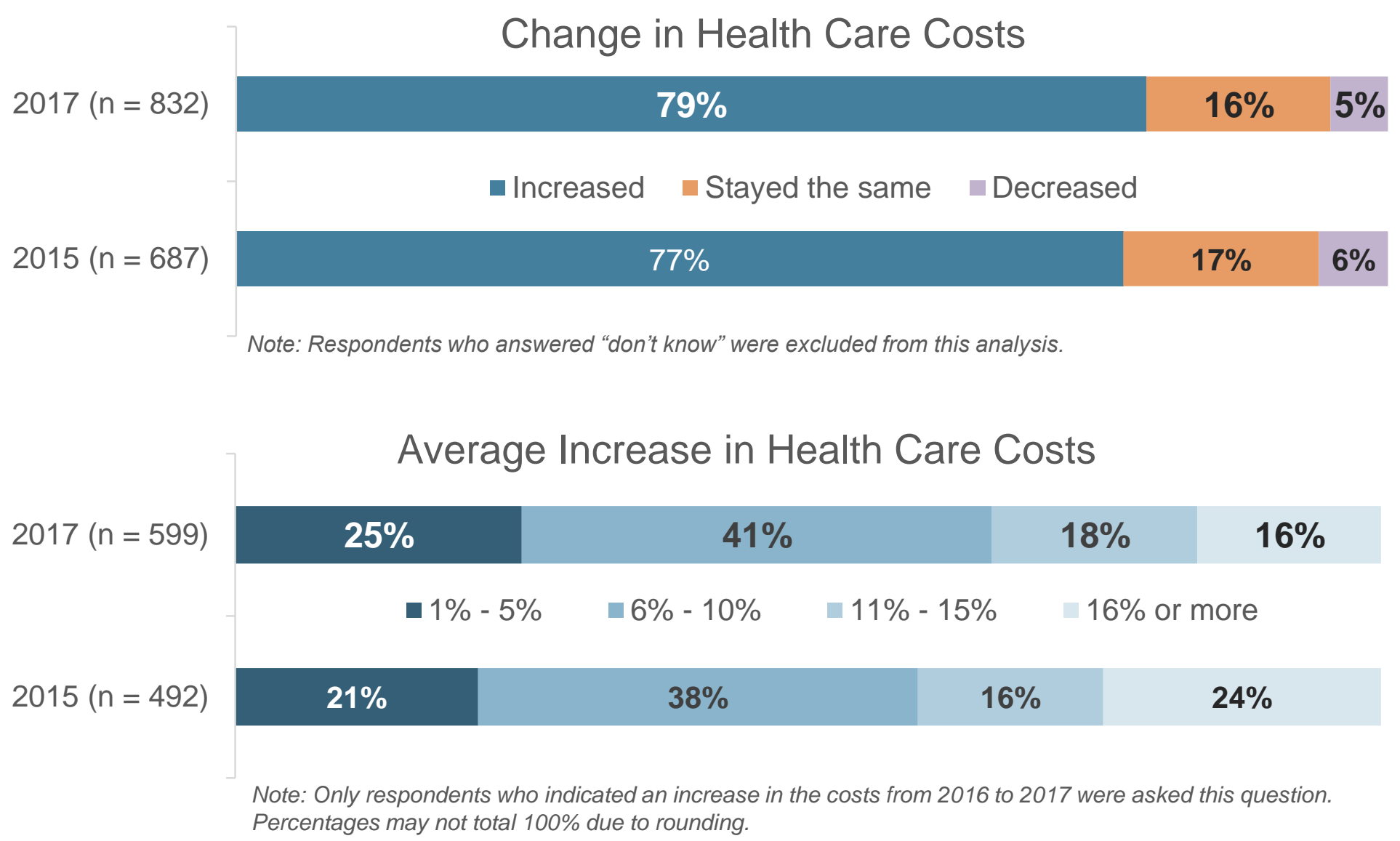




\section{Most employee benefits offerings have stayed the same since the ACA's implementation}

Similar to prior years, $20 \%$ of organizations reduced health care benefits offerings and $10 \%$ reduced non-health benefits offerings in order to control health care costs.

Health care benefits offerings

Non-health benefits offerings

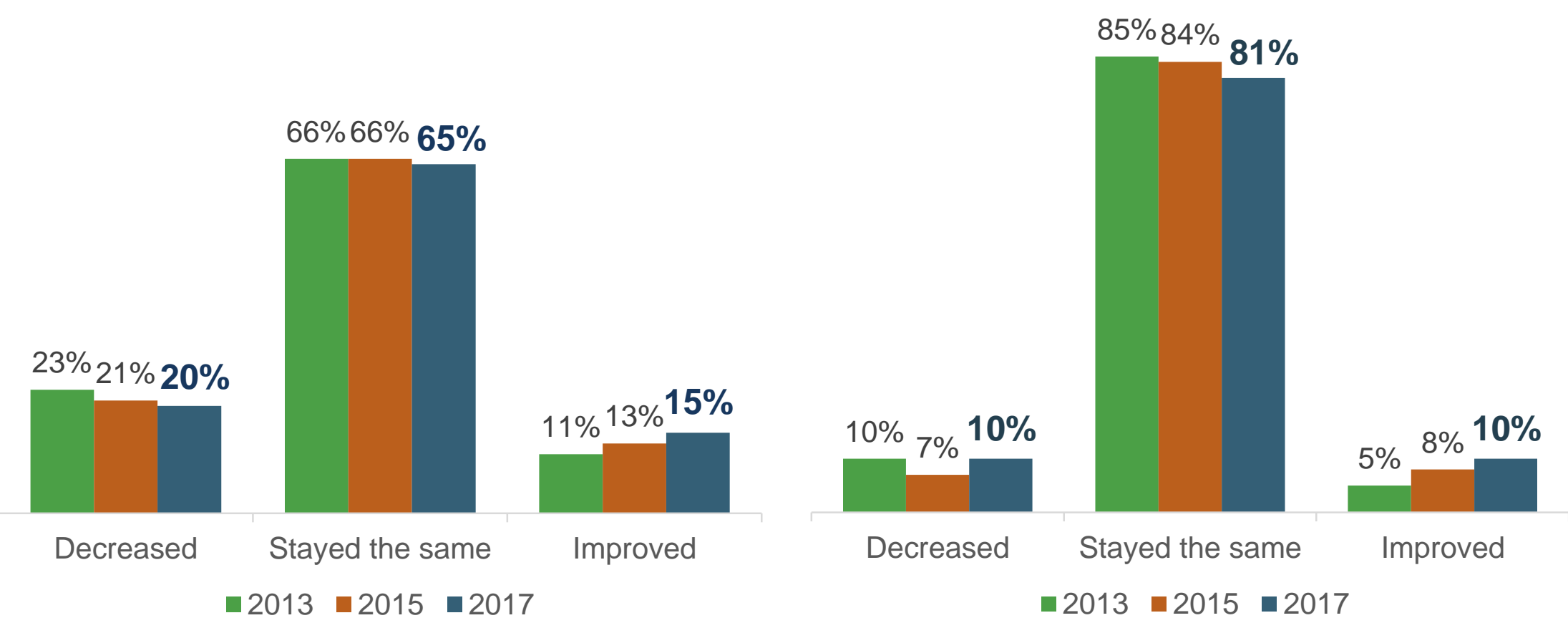

Note: $n=651-821$. Percentages may not total $100 \%$ due to rounding. Respondents who answered "don't know" were excluded from this analysis. 


\section{When cutting non-health benefits, organizations were most likely to reduce compensation}

Of the $10 \%$ of organizations that decreased non-health benefits in $2017,49 \%$ cut financial and compensation benefits, $47 \%$ cut professional and career development benefits, $46 \%$ cut employee programs and services, and $31 \%$ cut retirement savings and planning benefits.

Financial and compensation benefits

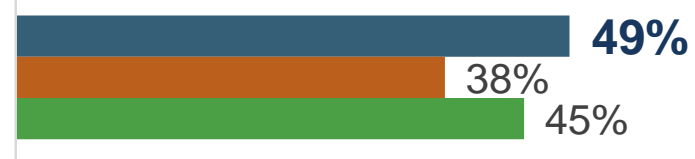

Professional and career development benefits

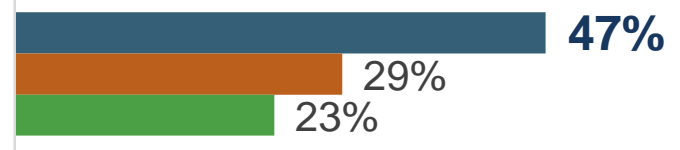

Employee programs and services

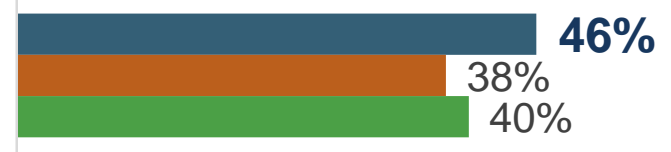

Retirement savings and planning benefits

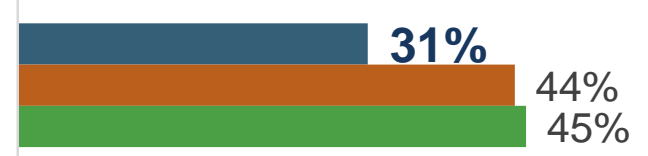

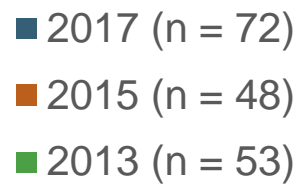

Note: Only respondents whose organizations decreased non-health-related employee benefits were asked this question. Percentages do not total 100\% due to multiple response options. Respondents who answered "don't know" were excluded from this analysis. 
$15 \%$

received medical loss ratio rebates in 2016.

Medical loss ratio rebates are mandated under the ACA whenever health insurers do not spend at least a certain percentage (generally, $80 \%$ to $85 \%$ ) of the prior year's health insurance premiums on health care services. If they fail to meet these standards, the insurance companies are required to provide a rebate to their customers (effective 2012).

Note: $n=274$. Respondents who answered "don't know" were excluded from this analysis.

\section{Majority distributed medical loss ratio rebates to employees}

Of the $15 \%$ of organizations that received medical loss ratio rebates in 2016 , more than one-half distributed either some (30\%) or the full amount (25\%) to employee participants in the plan.

Distributed a proportion to employee participants in the plan

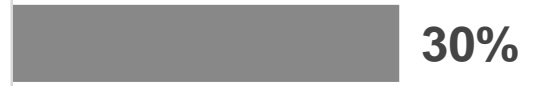

Applied toward future participant premium payments

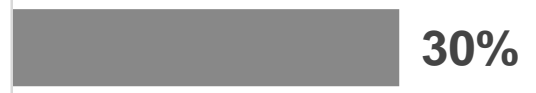

Distributed the full amount to employee participants in the plan

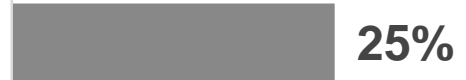

Applied toward other benefit enhancements

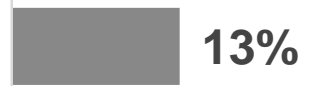

Other $10 \%$

Note: $n=40$. Only respondents whose organizations received rebates were asked this question. Percentages do not total $100 \%$ due to multiple response options. Respondents who answered "don't know" were excluded from this analysis. 


\section{Most organizations' definition of full-time employees is consistent with the ACA}

Many organizations (59\%) already use the same definition of full-time employees as the ACA-an average of at least 30 hours per week in a month-but some (19\%) changed their definition to match the ACA to make it easier to administer health care benefits.

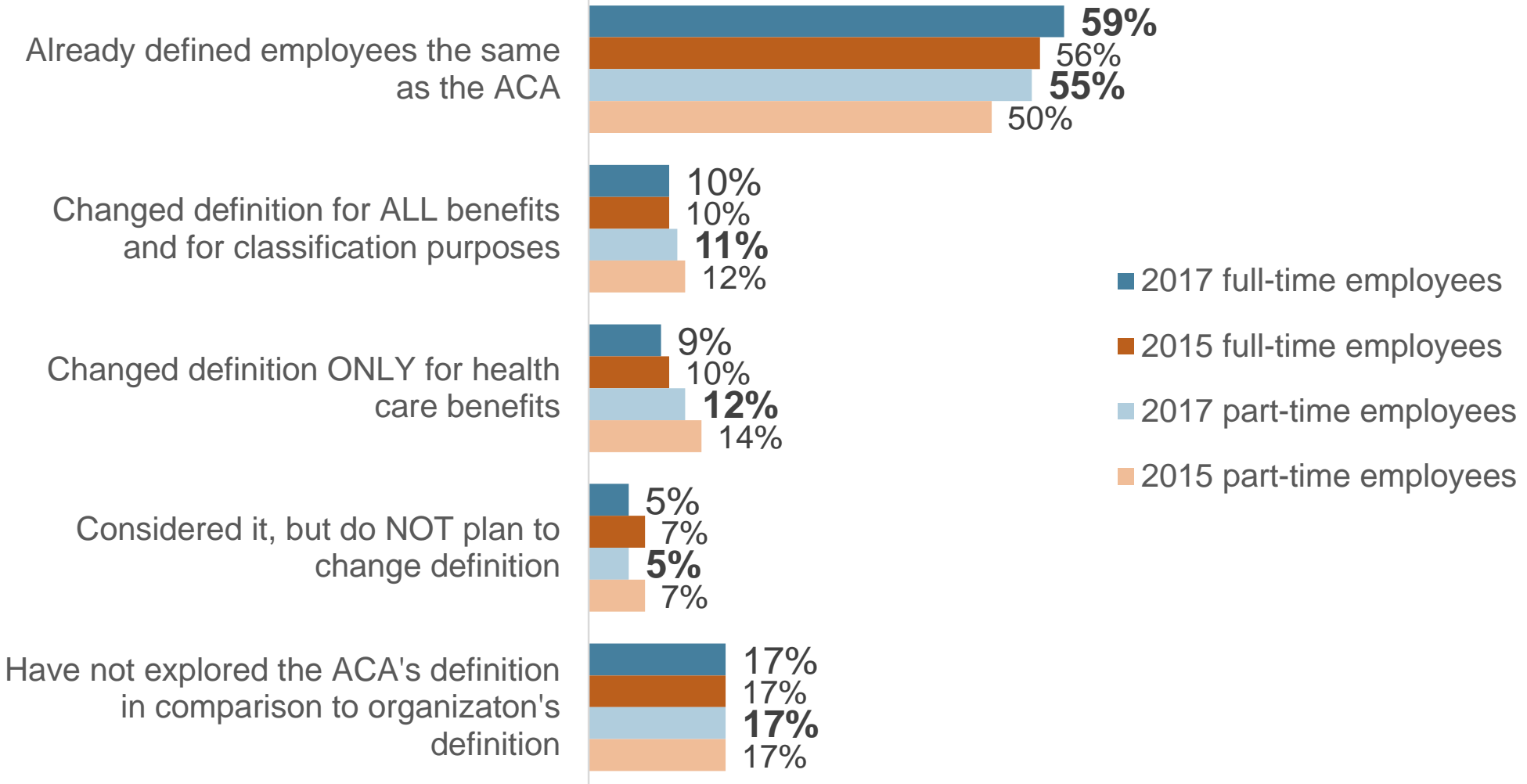

Note: $n=638-825$. Respondents who answered "don't know" or "not applicable" were excluded from this analysis. 


\section{Employer Mandate} (Play or Pay)

Under the ACA, employers with 50 or more full-time equivalent employees (FTEs) working an average of at least 30 hours per week (including the sum of hours by part-time employees that added together equal "equivalent" full-time employees) must offer full-time employees and their dependents affordable health care coverage, or be subject to penalties.

\section{Threshold of work hours required for health care coverage is reduced}

Compared with 2013 and 2014, fewer hours were required for full-time employee health care coverage. However, coverage for part-time workers (less than 30 hours per week) decreased from 28\% to 20\% compared with 2013.

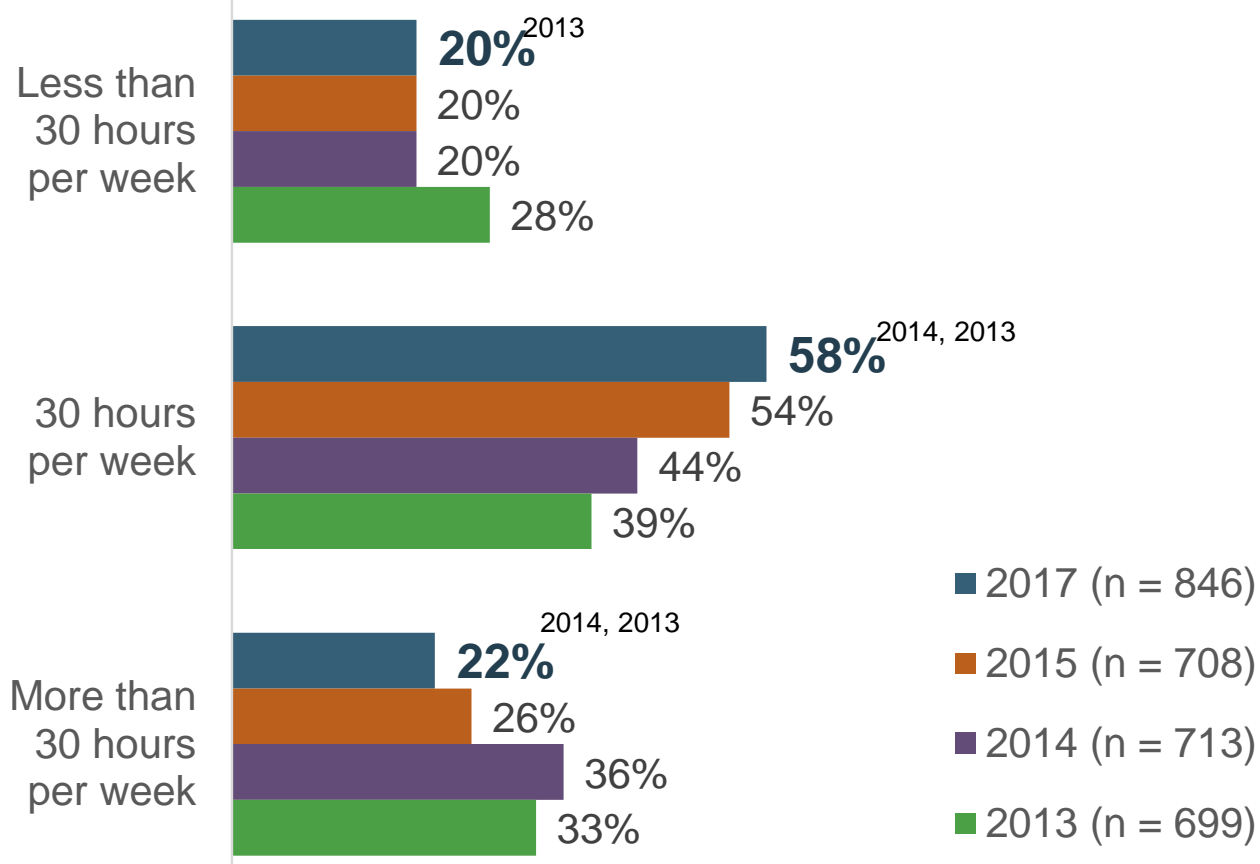

Note: Respondents who answered "don't know" or "N/A, no coverage offered" were excluded from this analysis.

2014 Statistically significant difference from 2014

2013 Statistically significant difference from 2013. 


\section{Some organizations have reduced part-time weekly hours as a result of the ACA}

Unchanged from 2015, 15\% of organizations have reduced hours for part-time employees below the 30-hourper-week threshold that would make them eligible for health care coverage under the ACA. Few (2\%) have reduced hours for full-time employees.

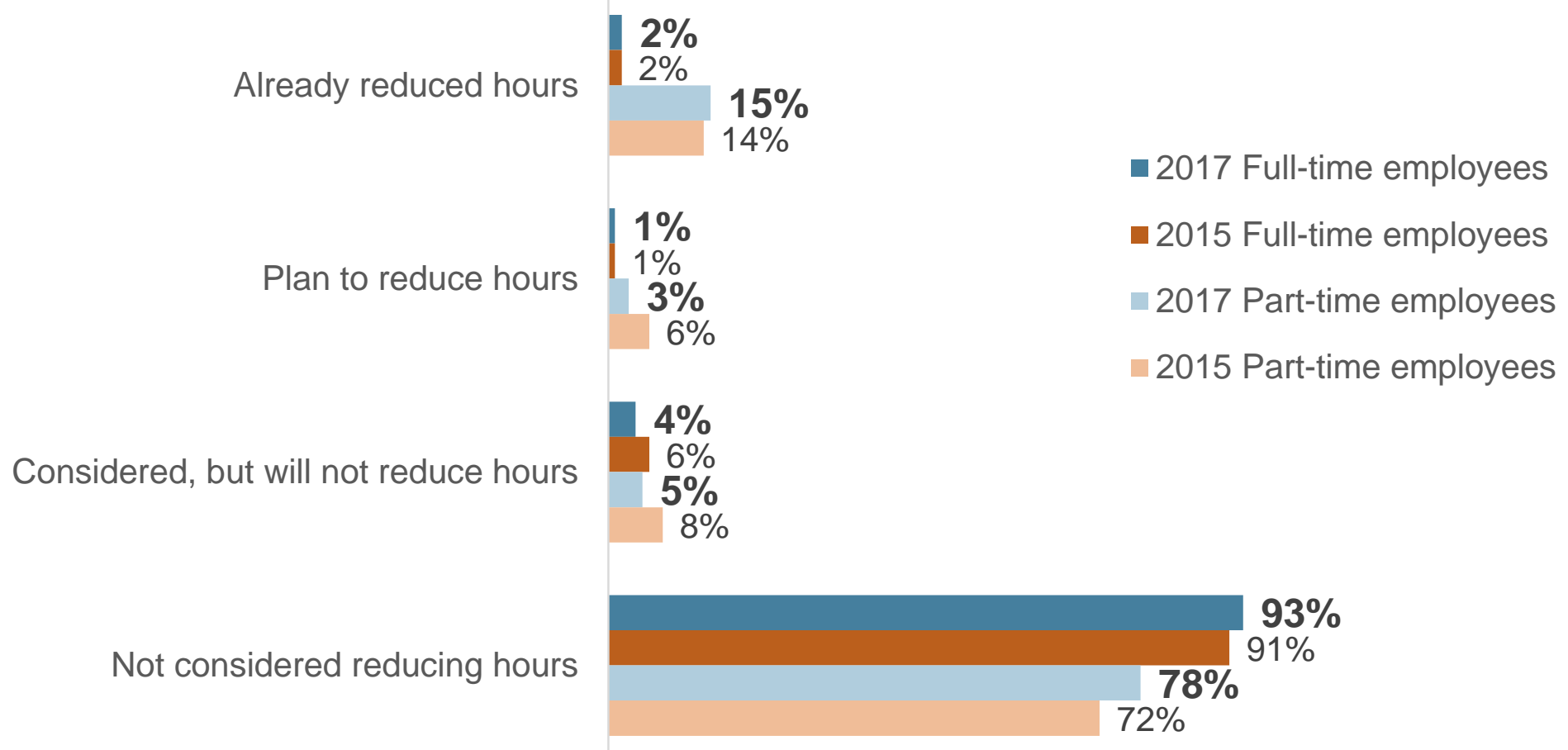

Note: $n=607-846$. Percentages may not total $100 \%$ due to rounding. Respondents who answered "don't know" or "N/A, we do not have this type of employee" were excluded from this analysis. 
Types of Health

Plans Offered by

Organizations

- $84 \%$ PPO

- $50 \%$ HSA

- $32 \% \mathrm{HMO}$

- $26 \%$ CDHP

- $21 \%$ POS

- $20 \%$ HRA

$\bullet 17 \%$ HDHP

- $9 \%$ EPO

- $7 \%$ Indemnity plan

- $2 \%$ Mini-med health plan

\section{$55 \%$ of organizations modified health care coverage in 2017}

The most common strategies to manage health care costs were offering alternative plans like health savings accounts (HSAs) or health reimbursement accounts (HRAs) (56\%) and promoting a culture of health and wellness (53\%).

Modified existing health
plan(s)

Added new health plan(s)

Changed health care provider(s)

Dropped previous health plan(s)

Other

No changes
$39 \%$

$41 \%$

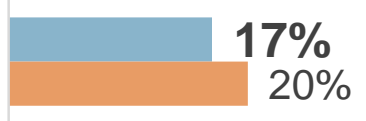

$11 \%$

$14 \% \quad-2017(n=832)$

$2015(\mathrm{n}=701)$

Note: Percentages do not total $100 \%$ due to multiple response options. Respondents who answered "don't know" were excluded from this analysis. 


\section{$16 \%$}

have a grandfathered health plan in 2017.

A "grandfathered health plan" is any group health plan or individual coverage that was in effect on the date of the ACA's enactment, March 23, 2010. If an employer maintains the same group health plan, it may be grandfatheredexempt from certain ACA provisions. A plan can lose its grandfathered status if certain changes are made-for example, if the plan significantly cuts or reduces benefits, raises co-insurance rates, significantly raises copayments or deductibles, or significantly lowers employer contributions, etc.

\section{Most grandfathered health care plans are fully ACA compliant}

Of the $16 \%$ of organizations that have a grandfathered health plan, $70 \%$ said the plan already meets all provisions of the ACA. In 2018, two-thirds (68\%) expect to keep grandfathered status-a total of $11 \%$ of organizations.

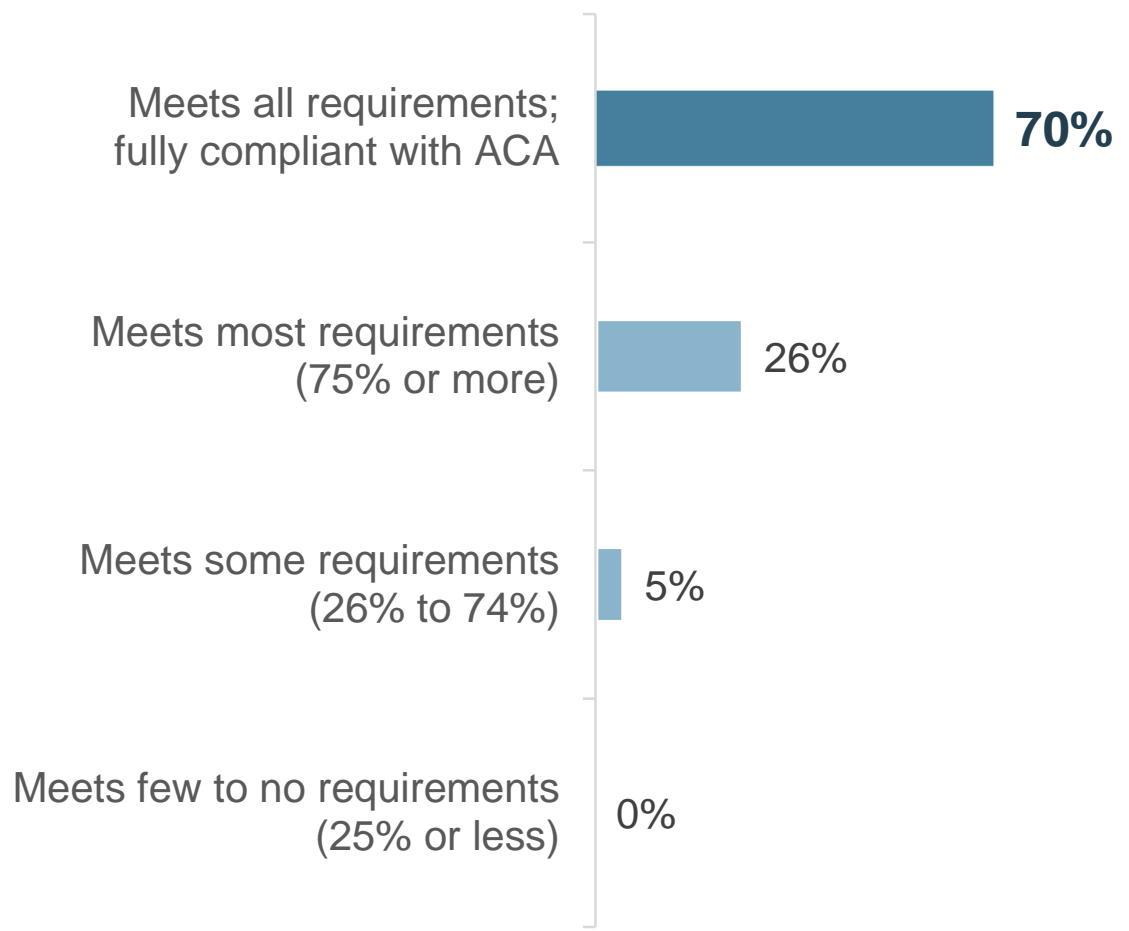

Note: $n=109$. Respondents who answered "don't know" were excluded from this analysis.

Note: $n=728$. Respondents who 


\section{Demographics: Organization Industry}

\begin{tabular}{|l|c|}
\hline \multicolumn{1}{|c|}{ Industry } & $\%$ \\
\hline Health care and social assistance & $17 \%$ \\
\hline Manufacturing & $15 \%$ \\
\hline $\begin{array}{l}\text { Professional, scientific and technical } \\
\text { services }\end{array}$ & $12 \%$ \\
\hline Educational services & $11 \%$ \\
\hline Finance and insurance & $11 \%$ \\
\hline Government agencies & $9 \%$ \\
\hline Construction & $5 \%$ \\
\hline Transportation and warehousing & $4 \%$ \\
\hline management and remediation services & $5 \%$ \\
\hline Utilities & $4 \%$ \\
\hline Retail trade & \\
\hline manistrative and support and waste & \\
\hline
\end{tabular}

\begin{tabular}{|l|c|}
\hline \multicolumn{1}{|c|}{ Industry } & $\%$ \\
\hline Accommodation and food services & $3 \%$ \\
\hline Real estate and rental and leasing & $3 \%$ \\
\hline Wholesale trade & $3 \%$ \\
\hline $\begin{array}{l}\text { Religious, grant-making, civic, } \\
\text { professional and similar organizations }\end{array}$ & $3 \%$ \\
\hline Information & $3 \%$ \\
\hline Arts, entertainment and recreation & $2 \%$ \\
\hline $\begin{array}{l}\text { Mining, quarrying, and oil and gas } \\
\text { extraction }\end{array}$ & $2 \%$ \\
\hline Repair and maintenance & $1 \%$ \\
\hline Agriculture, forestry, fishing and hunting & $1 \%$ \\
\hline Personal and laundry services & $1 \%$ \\
\hline Other industry & $10 \%$ \\
\hline
\end{tabular}

Note: $n=832$. Percentages do not total $100 \%$ due to multiple response options. 


\section{Demographics: Organization Sector and Staff Size}

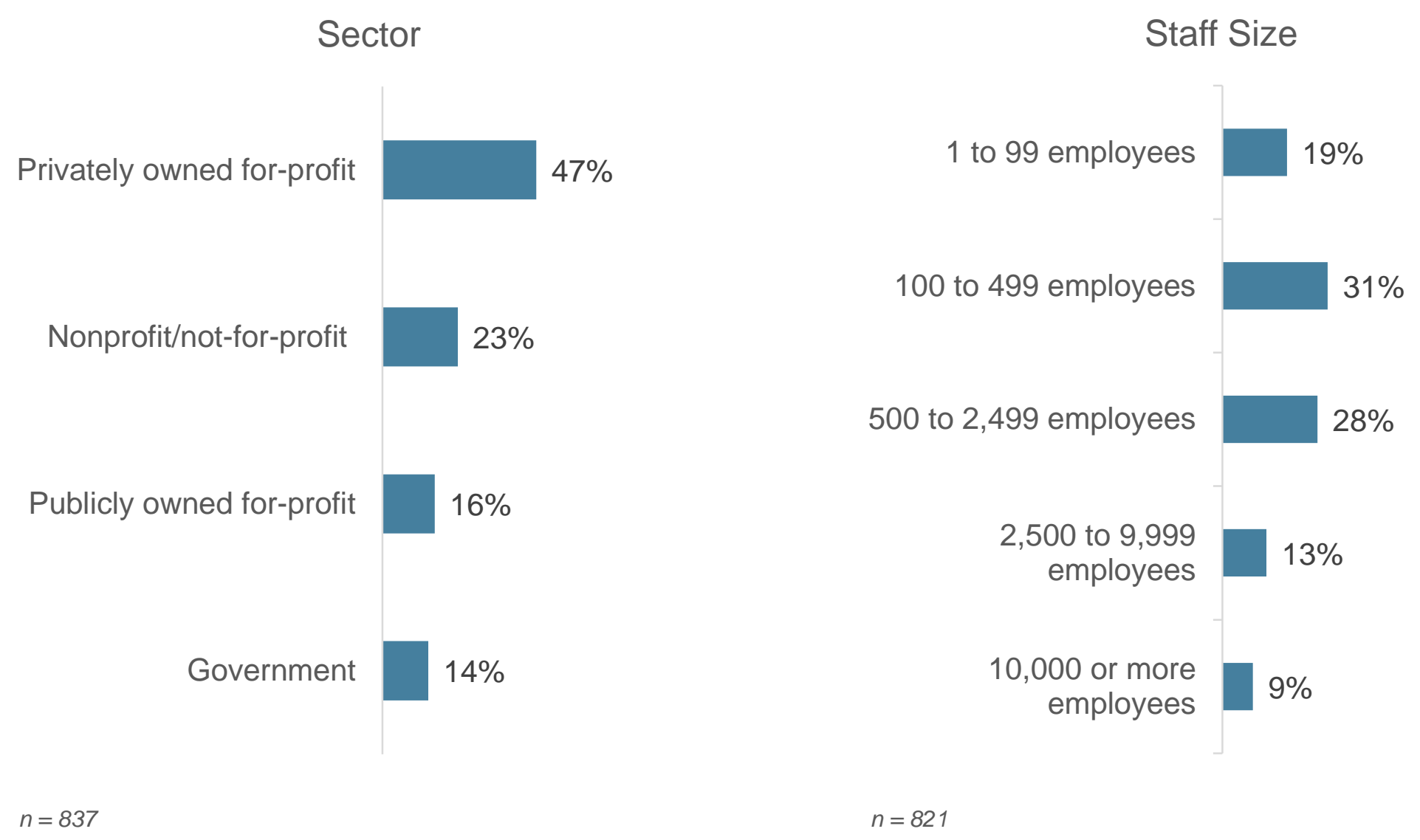




\section{Demographics: Other Organization Information}

\section{Region}

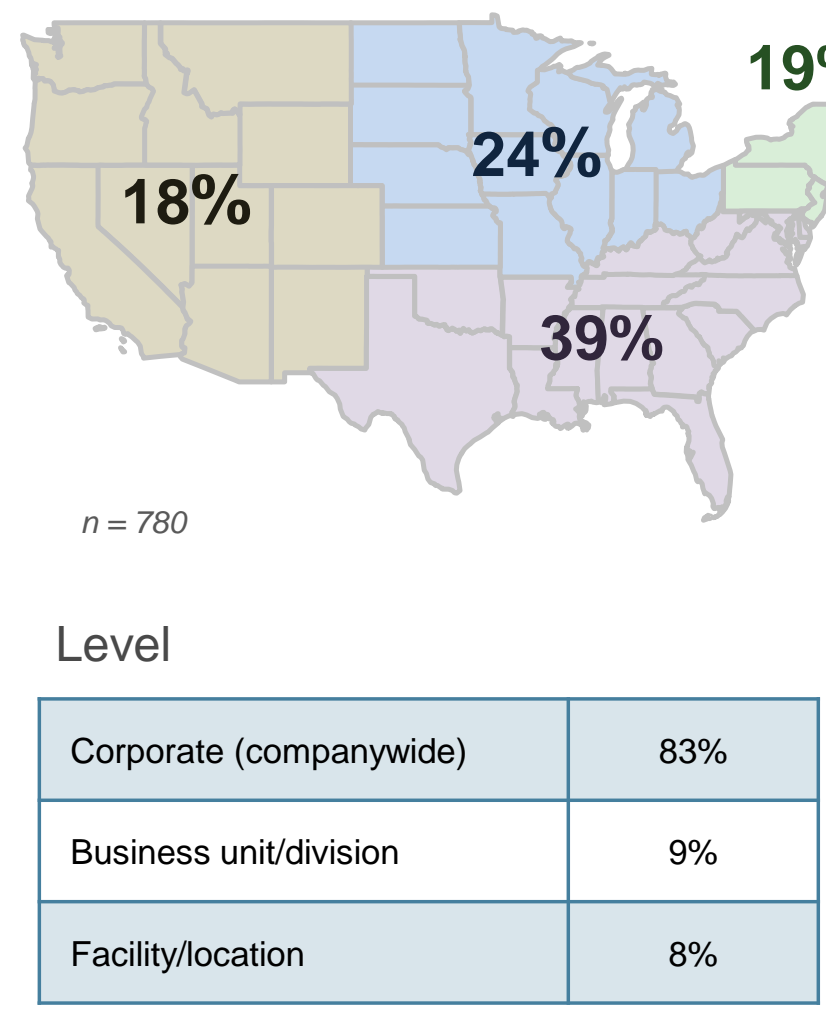

Note: $n=528$. These data represent organizational level from which the respondent answered the survey questions.
U.S. vs. Multinational

\begin{tabular}{|l|c|}
\hline U.S.-based operations only & $82 \%$ \\
\hline Multinational operations & $18 \%$ \\
\hline
\end{tabular}

$n=853$

Multi-Unit vs. Single Unit (U.S. based)

\begin{tabular}{|l|c|}
\hline $\begin{array}{l}\text { Multi-unit organization: An organization that } \\
\text { has more than one location. }\end{array}$ & $60 \%$ \\
\hline $\begin{array}{l}\text { Single-unit organization: An organization in } \\
\text { which the location and the organization are } \\
\text { one and the same. }\end{array}$ & $40 \%$ \\
\hline
\end{tabular}

$n=850$

Origin of Policy Decisions (Multi-Unit)

\begin{tabular}{|l|c|}
\hline Multi-unit headquarters & $62 \%$ \\
\hline Each work location & $2 \%$ \\
\hline $\begin{array}{l}\text { A combination of both the work location and } \\
\text { the multi-unit headquarters }\end{array}$ & $36 \%$ \\
\hline
\end{tabular}

$n=530$ 


\section{SHRM Survey Findings: Health Care Reform}

\section{Survey Methodology}

- Response rate $=16 \%$

- 918 HR professionals from a randomly selected sample of SHRM's membership with the job function of benefits or compensation or with the job title of manager or above participated in this survey.

- Margin of error $+/-3 \%$

- Survey fielded Feb. 9-24, 2017

\section{Project lead:}

Tanya Mulvey, researcher, SHRM Research

\section{Project contributors:}

Evren Esen, SHRM-SCP, director, workforce analytics, SHRM Research

Chatrane Birbal, senior advisor,

Government Relations

Samantha DiNicola, SHRM Research

Copy editor:

Katya Scanlan, SHRM Knowledge Center 


\section{Additional Resources}

\section{SHRM Research}

- Research and Surveys: shrm.org/research

- Special Reports and Expert Views: shrm.org/trends

- Labor Market and Economic Data: shrm.org/jos

SHRM Member Resources

- Health Care Reform Resources

- SHRM Health Care Legislative Updates

\section{Other SHRM Resources}

- Effective Practice Guidelines

Books and Resources, Events, Education and Certification

- shrmstore.org

\section{SHRM Business Solutions}

- Employee Engagement Survey: shrm.org/PeoplelnSight

- Benchmarking Service: shrm.org/Benchmarks

- Salary Data Service: shrm.org/SHRMCompensationDataCenter

\section{Other Resources}

- Bureau of Labor Statistics 